\title{
Rejection of Organic Micropollutants by Clean and Fouled Nanofiltration Membranes
}

\author{
Lifang $\mathrm{Zhu}^{1,2}$ \\ ${ }^{1}$ Department of Environmental Science, Zhejiang University, Hangzhou 310058, China \\ ${ }^{2}$ Department of Municipal Engineering, Zhejiang University of Water Resources and Electric Power, Hangzhou 310018, China
}

Correspondence should be addressed to Lifang Zhu; zhulifang1010@zju.edu.cn

Received 5 February 2015; Revised 18 April 2015; Accepted 21 April 2015

Academic Editor: Núria Fontanals

Copyright (C) 2015 Lifang Zhu. This is an open access article distributed under the Creative Commons Attribution License, which permits unrestricted use, distribution, and reproduction in any medium, provided the original work is properly cited.

The rejection of organic micropollutants, including three polycyclic aromatic hydrocarbons (PAHs) and three phthalic acid esters (PAEs), by clean and fouled nanofiltration membranes was investigated in the present study. The rejection of organic micropollutants by clean NF90 membranes varied from 87.9 to more than $99.9 \%$, while that of NF270 membranes ranged from 32.1 to $92.3 \%$. Clear time-dependence was observed for the rejection of hydrophobic micropollutants, which was attributed to the adsorption of micropollutants on the membrane. Fouling with humic acid had a negligible influence on the rejection of organic micropollutants by NF90 membranes, while considerable effects were observed with NF270 membranes, which are significantly looser than NF90 membranes. The observed enhancement in the rejection of organic micropollutants by fouled NF270 membranes was attributed to pore blocking, which was a dominating fouling mechanism for loose NF membranes. Changes in the ionic strength (from 10 to $20 \mathrm{mM}$ ) reduced micropollutant rejection by both fouled NF membranes, especially for the rejection of dimethyl phthalate and diethyl phthalate by NF270 membranes (from 65.8 to $25.0 \%$ for dimethyl phthalate and 75.6 to $33.3 \%$ for diethyl phthalate).

\section{Introduction}

Due to the growing demand for high quality water, applications employing membrane processes for water treatment have increased rapidly. Nanofiltration (NF) and reverse osmosis (RO) are promising membrane technologies that have been recognized as reliable and affordable techniques for the production of high quality water from nontraditional sources such as polluted surface water and secondary treated effluent, which require the removal of organic micropollutants [1-6]. The rejection mechanism of organic micropollutants by NF has been investigated in previous studies, and researchers agree that steric hindrance (or size exclusion) is the most important mechanism of uncharged organic micropollutant rejection $[7,8]$. Nevertheless, other micropollutants and membrane physicochemical properties may also influence the separation behavior. The results from various investigations showed that the adsorption of hydrophobic neutral compounds to membranes enhanced rejection and adsorption, which increased almost linearly with the distribution coefficient $(\log D)$, although the observed enhancement was most likely limited to a relatively short time scale [9, 10]. In many previously reported publications, the removal of organic micropollutants by NF has been described; however, only a few studies have been devoted to the time frame prior to rejection, and the rejection efficiency of an NF membrane for a hydrophobic compound will be overestimated if it is determined during short-term experiments $[7,11]$.

The fouling of NF membranes changes the membrane characteristic and affects the rejection of micropollutants. Natural organic matter (NOM) such as humic acid is one of the major causes of membrane fouling. Numerous studies have reported the physical and chemical aspects of NF membranes fouled by humic acid [12-15]. The influence of membrane fouling on the rejection of micropollutants by NF has also been studied. Membrane fouling can either increase or decrease the rejection of organic micropollutants by NF membranes $[5,13,16,17]$. The mechanisms of 
the different effects of fouling on the rejection of micropollutants have been illustrated. For instance, Nghiem and Hawkes [8] observed a considerable increase in rejection of trace organics by loose NF membrane under fouled conditions. The observed rejection increase was attributed to pore blocking. After fouled with sodium alginate, YangaliQuintanilla et al. [7] observed a decline in rejection of hydrophilic neutral compounds by NF200 membrane; however, they attributed the general trend of decreasing rejection to the phenomenon of "cake-enhanced concentration polarization." More recently, Shen et al. [18] investigated the influence of solute-solute interactions on hormone rejection during nanofiltration and observed that solute-solute interactions between humic acid (HA) and micropollutants improved micropollutant rejection and decreased micropollutant adsorption to membranes. HA sorption was attributed to enhanced water permeability due to the opening of charged membrane pores. In summary, many studies on the effects of membrane fouling on the NF of organic micropollutants have been reported, but the results of the aforementioned studies are highly variable. Certainly, the variety of commercially available micropollutants and membranes is the most probable cause of the observed discrepancies in previous results.

Recently, polycyclic aromatic hydrocarbons (PAHs) and phthalic acid esters (PAEs) have been frequently detected at higher concentrations in surface water [19-22]. Due to their toxicity, mutagenicity, and carcinogenic potential, PAHs are included in the priority list of pollutants of the US EPA and the European Union [23]. PAEs are a group of chemicals with high environmental relevance due to their production rates and ecotoxicological potential. Various adverse effects, including those on the reproductive and endocrine systems of crustaceans and amphibians, have been reported [24-26]. Thus, the occurrence and removal of PAHs and PAEs have become a significant focus in the field of water treatment. PAHs and PAEs are difficult to remove by conventional water treatment technology; however, until now, little information on the removal of PAHs and PAEs by NF membranes has been provided. Furthermore, dimethyl phthalate and diethyl phthalate present low hydrophobicity, while all PAHs are highly hydrophobic. Thus, the nanofiltration of PAHs and PAEs can improve the understanding of the relationship between the hydrophobicity of compounds and rejection by NF.

The aim of the present study was to investigate the rejection of PAHs and PAEs by NF membranes and to explain the effects of polymeric NOM on the removal efficiency. Filtration experiments were carried out on three types of PAHs and PAEs, including dimethyl phthalate, diethyl phthalate, dibutyl phthalate, acenaphthylene, phenanthrene, and pyrene, using two different commercial NF membranes.

\section{Materials and Methods}

2.1. Membranes and Chemicals. Two thin-film composite NF membranes, denoted as NF270 and NF90 (Dow FilmTec), were employed in the present investigation. The membranes were received as flat sheet samples and were stored dry at $4^{\circ} \mathrm{C}$.

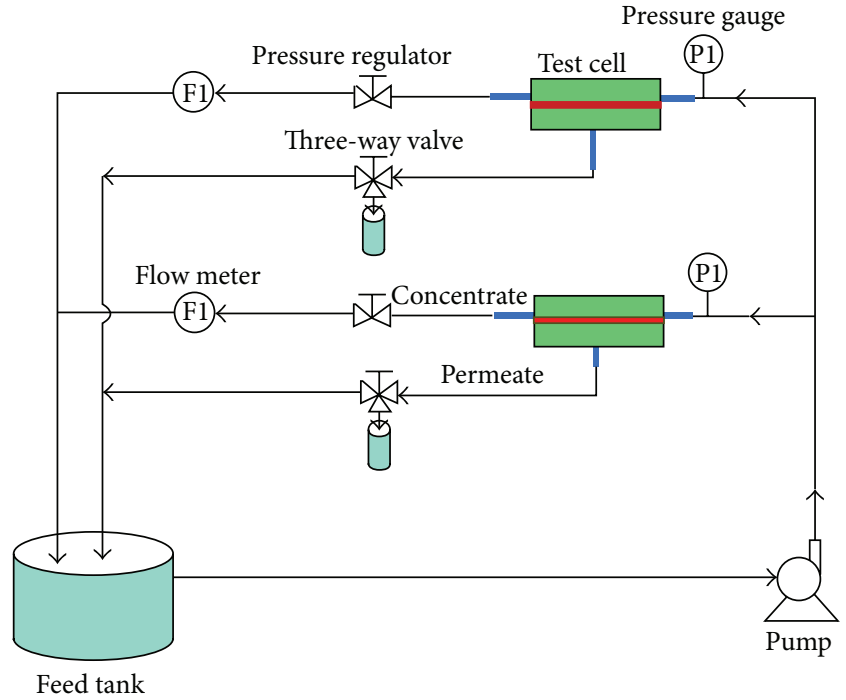

Figure 1: The cross-flow filtration unit in this study.

Dimethyl phthalate, diethyl phthalate, and dibutyl phthalate, which possessed a purity of $99.5 \%$, were purchased from Sinopharm. Acenaphthylene was purchased from TCI and possessed a purity of $99 \%$. Phenanthrene was purchased from Acros and presented a purity of $98 \%$. Pyrene was purchased from $J \& K$ and possessed a purity of $98 \%$. Table 1 shows the key physicochemical parameters of these compounds. Methanol was purchased from Amethyst and had HPLC grade. The feed solutions were prepared by spiking an appropriate amount of dimethyl phthalate and diethyl phthalate from a water-based stock solution into Milli-Q water. For the other chemicals, the stock solutions were prepared by dissolving the compound in methanol. For all of the tested compounds, the experiments were performed at a feed concentration of approximately $500 \mu \mathrm{g} \mathrm{L}^{-1}$, except for dimethyl phthalate, which was evaluated at a feed concentration of $800 \mu \mathrm{g} \mathrm{L}^{-1}$. In all of the experiments, three PAHs and three PAEs were mixed in a single feed solution. Humic acid was used in the present study and was obtained from Sinopharm.

2.2. Membrane Test Unit. A laboratory-scale, cross-flow membrane test unit with two parallel cells was used in the current study (Figure 1). The experiments were conducted in recycle mode, in which the retentate and permeate were returned to the feed reservoir to maintain a constant concentration. The membrane cell and tubes were made of stainless steel to minimize compound losses on nonmembrane components of the test system. The feed reservoir $(4 \mathrm{~L})$ was made of glass. For each experiment, a new membrane coupon with an effective membrane area of $22.05 \mathrm{~cm}^{2}$ was used. The experiments were conducted at ambient temperature $(25 \pm$ $\left.1^{\circ} \mathrm{C}\right)$.

2.3. Experimental Protocol. Prior to each experiment, the membrane was stabilized at $500 \mathrm{kPa}$ using deionized water until the permeate flux reached a constant value. After 
TABLE 1: Physicochemical properties of the compounds tested in this study.

\begin{tabular}{|c|c|c|c|c|c|}
\hline Compound & $\begin{array}{c}\mathrm{MW} \\
\left(\mathrm{g} \mathrm{mol}^{-1}\right)\end{array}$ & $\begin{array}{c}\text { Solubility } \\
\left(\mathrm{mg} \mathrm{L}^{-1}\right)\end{array}$ & $\log K_{\mathrm{ow}}$ & Chemical structure & CAS number \\
\hline Acenaphthylene & 154 & 16.1 & 3.92 & & $208-96-8$ \\
\hline Phenanthrene & 178 & 1.15 & 4.46 & & $85-01-8$ \\
\hline Pyrene & 202 & 0.135 & 4.88 & & $129-00-0$ \\
\hline Dimethyl phthalate & 194 & 4000 & 1.6 & & $131-11-3$ \\
\hline Diethyl phthalate & 222 & 1080 & 2.42 & & $84-66-2$ \\
\hline Dibutyl phthalate & 278 & 11.2 & 4.5 & & $84-74-2$ \\
\hline
\end{tabular}

membrane stabilization, water was replaced by the solution in the feed reservoir, which contained the tested compounds. Feed and permeate samples $(1 \mathrm{~mL}$ each) were obtained at specified time intervals for analysis.

The fouling of membranes and subsequent rejection experimental protocol were conducted in three steps, including compaction, fouling development, and rejection measurement. First, the membrane was compacted using Milli$\mathrm{Q}$ water at $500 \mathrm{kPa}$ for at least $2 \mathrm{~h}$ until a stable baseline flux was obtained. A fouling layer was then allowed to develop using a solution consisting of $50 \mathrm{mg} \mathrm{L}^{-1}$ of humic acid, and a stable flux was again obtained prior to the addition of the tested compounds in an electrolyte solution. The electrolyte solution was used to produce a foulant cocktail with a $\mathrm{NaCl}$ concentration of $10 / 20 \mathrm{mM}$. The fouling layer was allowed to develop until changes in the flux were no longer observed.

2.4. Analysis. A high performance liquid chromatography (HPLC, Aglient 1260) system equipped with a reverse phase C18 column was employed to determine PAHs and PAEs using methanol and water as mobile phase with gradient elution. Acenaphthylene, phenanthrene, and pyrene were determined by fluorescence detector with excitation/emission wavelengths of $225 \mathrm{~nm} / 360 \mathrm{~nm}, 244 \mathrm{~nm} / 360 \mathrm{~nm}$, and $237 \mathrm{~nm} / 385 \mathrm{~nm}$, respectively. PAEs were determined by ultraviolet detector with wavelength of $230 \mathrm{~nm}$. The limits of detection (LOD) for acenaphthylene, phenanthrene, pyrene, dimethyl phthalate, diethyl phthalate,anddibutyl phthalate were $0.003 \mathrm{mg} \mathrm{L}^{-1}, 0.006 \mathrm{mg} \mathrm{L}^{-1}, 0.022 \mathrm{mg} \mathrm{L}^{-1}, 0.018 \mathrm{mg} \mathrm{L}^{-1}$, $0.007 \mathrm{mg} \mathrm{L}^{-1}$, and $0.019 \mathrm{mg} \mathrm{L}^{-1}$, respectively.

2.5. Measurement of Contact Angle. Contact angle measurements were performed with a DSA10-MK2 contact angle analyzer (KRUSS BmbH Co., Germany). The sessile drop method was used to measure the contact angles of deionized water $(3 \mathrm{~L})$ on the dried surfaces of the membranes at $25^{\circ} \mathrm{C}$. The volume of drop was $5 \mu \mathrm{L}$. Images were captured $5 \mathrm{~s}$ after introducing the drop and the contact angles were calculated. At least ten measurements on different locations of the membrane sample were performed and averaged to obtain the contact angle of the measured membrane sample. All the results presented were an average data from five membrane samples with standard deviation of the measured values.

\section{Results and Discussion}

3.1. Membrane Characteristics. The nanofiltration membranes assessed in the present study consisted of a thin active layer on top of a porous polysulfone backing layer. The active 
TABLE 2: Comparison of clean and fouled membrane properties.

\begin{tabular}{lcccc}
\hline \multirow{2}{*}{ Characteristic } & \multicolumn{2}{c}{ NF90 } & \multicolumn{2}{c}{ NF270 } \\
& Clean & Fouled & Clean & Fouled \\
\hline $\begin{array}{l}\text { Contact angle }\left(^{\circ}\right) \\
\begin{array}{l}\text { Pure water permeability } \\
\left(\mathrm{L} \mathrm{m}^{-2} \mathrm{~h}^{-1}\right)\end{array}\end{array}$ S7.3 $^{\circ} .0$ & $61.5 \pm 2.2$ & $26.1 \pm 2.1$ & $30.8 \pm 2.1$ \\
\hline
\end{tabular}

layer of the NF270 membrane was made of semiaromatic piperazine-based polyamides, while the NF90 membrane possessed a fully aromatic polyamide active layer. The two membranes displayed quite distinct characteristics. NF90 was a relatively tight NF membrane with an average pore diameter of only $0.68 \mathrm{~nm}$. In contrast, NF270 can be considered a loose NF membrane $(0.84 \mathrm{~nm})$ [13]. Salt rejection tests were carried out to simulate the standard conditions indicated by the membrane datasheets. The average rejection of sodium sulfate by clean NF270 and NF90 membranes was $97.8 \%$ and $98.7 \%$, respectively. The pure water permeability and contact angle of clean and fouled membranes are shown in Table 2. As described in the table, NF270 was more permeable than NF90 but provided lower solute rejection efficiencies. The contact angle indicates the hydrophobicity of the membrane surface. In the current study, NF90 had a larger contact angle and possessed a more hydrophobic surface. An increase in the hydrophobicity was clearly observed by a considerable increase in the contact angle of both membranes fouled with humic acid compared to that of clean membranes.

3.2. Variation of Tested Compounds during the Filtration Tests. The concentration of all six compounds in permeate and feed, as a function of the filtration time by NF270 and NF90 membranes, is presented in Figure 2. The concentration of acenaphthylene, phenanthrene, pyrene, and dibutyl phthalate in the feed solution decreased over time. The observed decrease was likely due to the adsorption of these compounds on the membrane because evaporation and adsorption onto the experimental system were negligible in the control tests (see Section 2). The feed concentration then stabilized as the adsorption of the compounds to the membrane reached equilibrium. In contrast to the results shown in Figures 2(a), 2(b), 2(c), and 2(f), the observed decrease in the concentration of dimethyl phthalate in the recirculated feed solution during NF270 and NF90 membrane filtration tests was low, as shown in Figures 2(d) and 2(e). The concentration of dimethyl phthalate and diethyl phthalate in permeate were stable throughout the tests, which may be attributed to the hydrophobicity of the contaminants used in this study. In other words, lower hydrophobicity of dimethyl phthalate and diethyl phthalate led to the lower adsorption by membrane. Compared to the aqueous phase, a highly hydrophobic solute preferentially adsorbs onto the membrane polymeric phase. Compounds with $\log K_{\text {ow }}$ values (logarithm of the octanolwater partitioning coefficient) less than 2.7 are considered to be of low hydrophobicity, and compounds with $\log K_{\text {ow }}>3$ are considered to be of high hydrophobicity [27]. Acenaphthylene, phenanthrene, pyrene, and dibutyl phthalate, which
TABLE 3: Rejection of organic micropollutants by NF90 and NF270.

\begin{tabular}{lcccc}
\hline Compound & $\begin{array}{c}\text { Clean } \\
\text { NF90 (\%) }\end{array}$ & $\begin{array}{c}\text { Fouled } \\
\text { NF90 (\%) }\end{array}$ & $\begin{array}{c}\text { Clean } \\
\text { NF270 (\%) }\end{array}$ & $\begin{array}{c}\text { Fouled } \\
\text { NF270 (\%) }\end{array}$ \\
\hline Acenaphthylene & 92.4 & 91.2 & 86.4 & 87.3 \\
Phenanthrene & 95.7 & 96.0 & 88.6 & 92.5 \\
Pyrene & $>99.9$ & $>99.9$ & 92.3 & $>99.9$ \\
Dimethyl phthalate & 87.9 & 95.0 & 32.1 & 65.8 \\
Diethyl phthalate & 95.3 & 92.0 & 50.4 & 75.6 \\
Dibutyl phthalate & $>99.9$ & $>99.9$ & 50.0 & 59.6 \\
\hline
\end{tabular}

are highly hydrophobic, as reflected by their high $\log K_{\text {ow }}$ values ( $>3.0)$, showed apparent adsorption to the membrane polymeric layer. In contrast, dimethyl phthalate and diethyl phthalate presented low hydrophobicity $\left(\log K_{\text {ow }}<2.7\right)$, and their adsorption to the membrane polymeric layer was not significant. Based on these results, the rejection efficiency of hydrophobic compounds should be determined after the adsorption of compounds to the membrane reaches equilibrium. In the present study, the rejection efficiency of acenaphthylene, phenanthrene, pyrene, and dibutyl phthalate was determined based on $8 \mathrm{~h}$ of filtration.

3.3. Rejection of Organic Micropollutants. The rejection of organics by NF membranes can be attributed to a number of mechanisms, the most common of which are steric interactions (or size exclusion), charge exclusion (repulsion), and adsorption to the membrane surface. The organic micropollutants investigated in the current study are undissociated at the $\mathrm{pH}$ evaluated in the experiments ( $\mathrm{pH} 7$ ). In this case, ionic (charge) interactions between trace organic contaminants and the membranes do not exist, and steric exclusion and adsorptive effects are expected to dominate.

The rejection efficiency of the organic solute was determined using

$$
R(\%)=\left(1-\frac{C_{p}}{C_{f}}\right) \times 100,
$$

where $R$ is the rejection and $C_{p}$ and $C_{f}$ are the solute concentrations in feed and permeate, respectively. The relationship between the feed and permeate concentration was converted into the rejection efficiency. Table 3 presents the rejection efficiencies of all six compounds by NF90 and NF270 membranes.

The results showed that the tight NF90 membrane showed significantly higher rejection efficiencies compared to the loose nanofiltration NF270 membrane for all of the tested compounds. The rejection of PAEs by NF270 was significantly lower than that of NF90, which was attributed to the MWCO of the membrane. For neutral compounds with low hydrophobicity, such as dimethyl phthalate and diethyl phthalate, adsorption and charge exclusion are very weak; thus, steric hindrance was the dominant mechanism during nanofiltration. The rejection of compounds with 


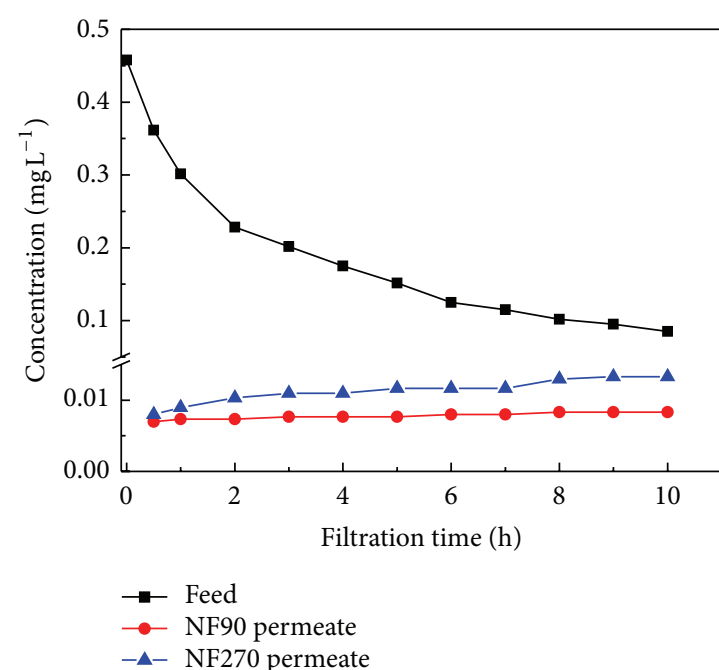

(a) Acenaphthylene

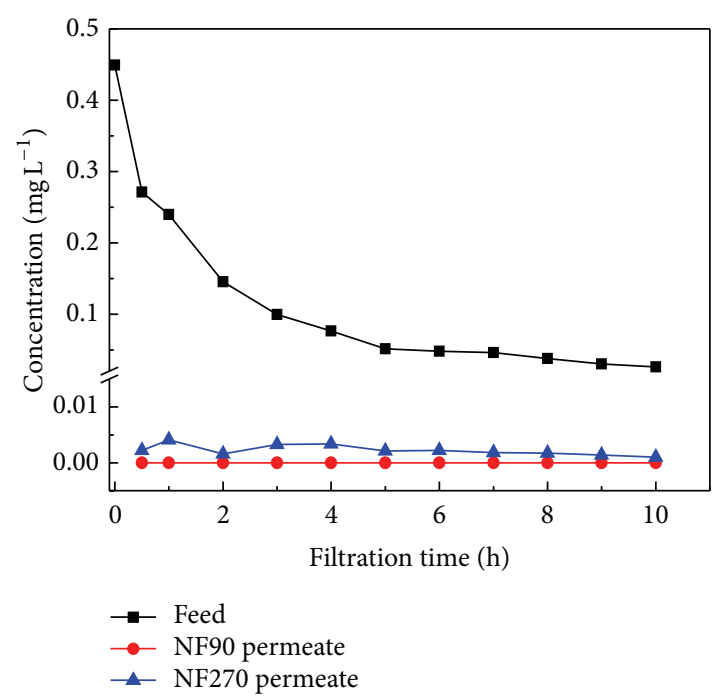

(c) Pyrene

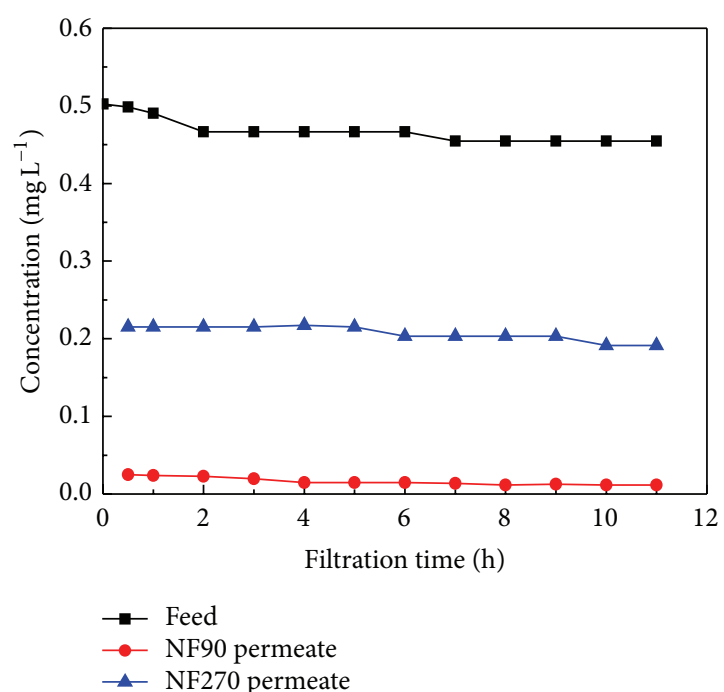

(e) Diethyl phthalate

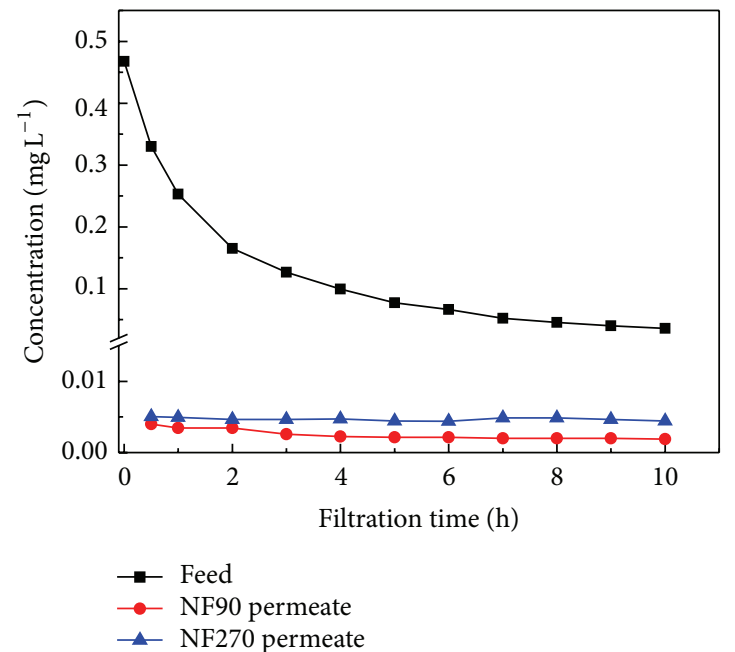

(b) Phenanthrene

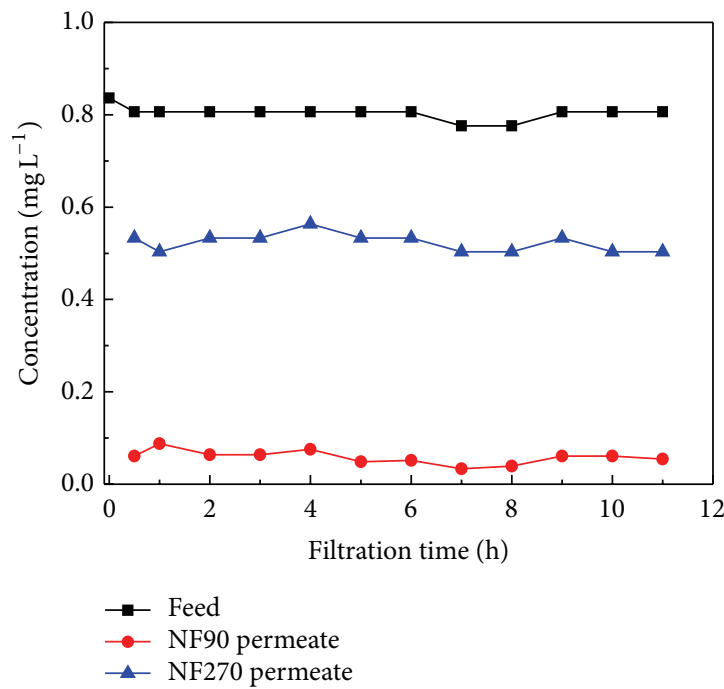

(d) Dimethyl phthalate

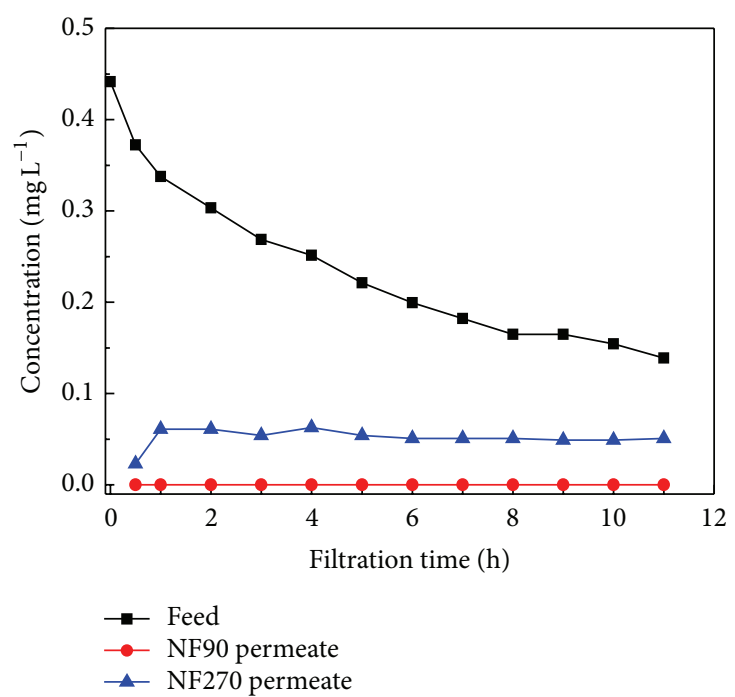

(f) Dibutyl phthalate

FIGURE 2: Change in concentration of (a) acenaphthylene, (b) phenanthrene, (c) pyrene, (d) dimethyl phthalate, (e) diethyl phthalate, and (f) dibutyl phthalate during filtration test (applied pressure: $500 \mathrm{kPa}$ ). 
molecular weights (MW of $194-278 \mathrm{~g} \mathrm{~mol}^{-1}$ ) similar to or greater than the MWCO of NF90 (200 Da) showed higher rejection rates. In contrast, for NF270 (300 Da), which possessed a higher MWCO than all of the MWs of the PAEs, lower rejection rates were observed. Moreover, the rejection of dibutyl phthalate, which possessed a higher $\log K_{\text {ow }}$ than dimethyl phthalate and diethyl phthalate, did not show significantly higher rejection efficiency by NF270. This observation was supported by Yangali-Quintanilla et al. [7], who found that larger hydrophobic neutral compounds (MW 216-272 $\mathrm{g} \mathrm{mol}^{-1}$ ) did not show considerably higher rejection rates by loose NF200 membranes than low MW hydrophilic neutral compounds (MW 151-194 $\mathrm{g} \mathrm{mol}^{-1}$ ) due to the diffusion of hydrophobic neutral compounds across the membrane after saturation. The rejection of all of the PAHs was high by both NF90 and NF270 and ranged from $86.4 \%$ to more than $99.9 \%$. The rejection of acenaphthylene and phenanthrene, which possess MWs $\left(154 \mathrm{~g} \mathrm{~mol}^{-1}\right.$ and $178 \mathrm{~g} \mathrm{~mol}^{-1}$ ) that are lower than the MWCO of both NF90 and NF270 membranes, showed greater rejection efficiencies. This result was attributed to the adsorption of compounds to the membrane polymer, as evidenced by a decrease in the feed concentration in the final stages of the experiment. According to Nghiem et al., the adsorption of compounds onto the membrane skin layer is fast and is not a rate-limiting step. Rather, the rate of transport across the membrane is governed by diffusion through the skin (active) layer of thinfilm composite NF membranes. Thus, the similar rejection rates of acenaphthylene, phenanthrene, and pyrene by tight NF90 and loose NF270 membranes were attributed to their comparable active layer thicknesses. Similar performances have also been observed for the rejection of natural hormones by NF90 and NF270 membranes [11].

\subsection{Effects of HA on the Membrane Rejection Behavior}

3.4.1. Membrane Fouling. The extent of membrane fouling can be described by the normalized permeate flux decline. The ratio of the permeate flux $(J)$ and initial pure water flux $\left(J_{0}\right)$ was calculated as an indicator of membrane fouling. Figure 3 presents the normalized permeate flux as a function of time during fouling by HA for NF270 and NF90 membranes. Similar to previous studies on membrane fouling behavior due to organic matter, two distinct fouling stages were observed $[8,28,29]$. A rapid flux decline occurred immediately after HA was introduced to the feed solution. Subsequently, a considerably slower flux decline was observed, and a quasi-steady-state fouling layer fully developed after approximately $12 \mathrm{~h}$ of filtration. The NF270 membrane exhibited a lesser decline (20\% reduction) due to fouling compared to the NF90 membrane, which presented a $30 \%$ reduction in the normalized specific flux. According to an atomic force microscopy (AFM) study performed by Boussu et al., the NF90 membrane surface (mean roughness of $38.8 \mathrm{~nm}$ ) is rougher than the NF270 membrane (mean roughness of $4.6 \mathrm{~nm}$ ). Previous studies indicated that rougher membranes are expected to foul to a greater degree than

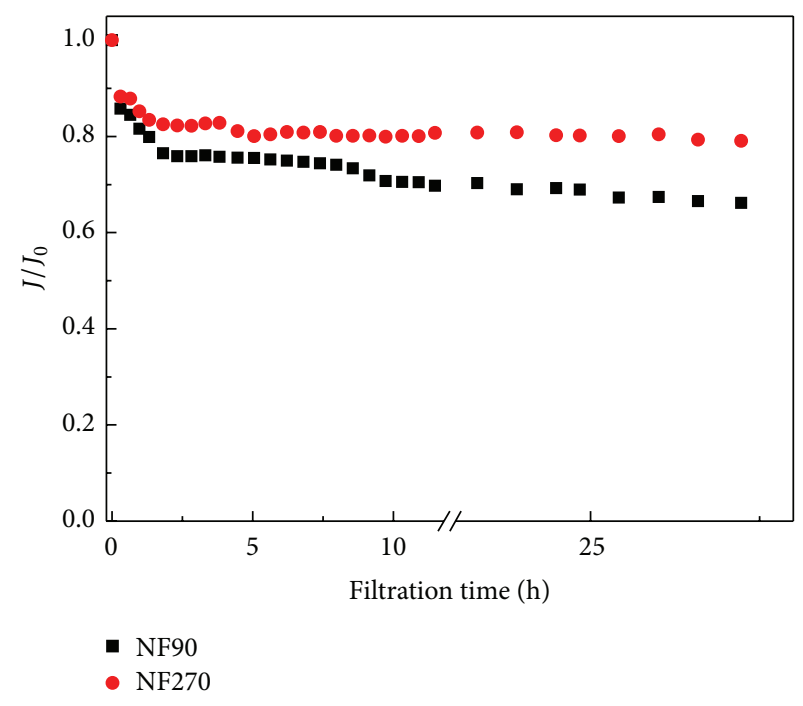

FIgURE 3: Normalized permeate flux of NF270 and NF90 membranes (applied pressure: $500 \mathrm{kPa}$; concentration of humic acid: $50 \mathrm{mg} \mathrm{L}^{-1}$ ).

smoother membranes. Thus, the higher flux decline for the NF90 membrane was attributed to its greater membrane roughness.

Compared to rejection by clean membranes, membrane fouling resulted in the modification of membrane properties and affected the rejection of organic micropollutants. A dark brown layer of humic foulant was firmly attached to the membrane surface after all of the fouling experiments. The characterization of fouled membranes showed that there was a significant change in membrane hydrophobicity after fouling (Table 2). The rejection rates of selected PAHs and PAEs by clean and fouled NF90 and NF270 membranes are presented in Table 3. More than $90 \%$ of contaminants was rejected by clean NF90 membranes and was not significantly affected by fouling, except for the rejection of dimethyl phthalate, which increased from $87.9 \%$ to $95.0 \%$ due to fouling. This result was consistent with those of previous studies performed by Nghiem and Hawkes [8]. The observed increase in the rejection of dimethyl phthalate by fouled NF90 membranes was attributed to an enhanced sieving effect. Regarding NF270 membranes, a significant enhancement in the rejection of compounds with low hydrophobicity, such as dimethyl phthalate and diethyl phthalate, was observed (raised 33.7\% and 25.2\%, resp.) due to fouling. The observed increase in rejection by fouled NF270 membranes, which have a larger pore size $(0.84 \mathrm{~nm})$, was attributed to pore blocking [8] and the increased hydrophobicity of fouled NF270 membranes. Furthermore, a small but nevertheless apparent increase in the rejection of the four hydrophobic compounds by NF270 membranes under fouled conditions was also observed, as shown in Table 3.

3.4.2. Effects of the Ionic Strength on Rejection. To study the effect of the ionic strength on rejection, the salt content of the feed solution was adjusted with $\mathrm{NaCl}(10$ and $20 \mathrm{mM})$ after the 
TABLE 4: Effect of ionic strength on rejection of compounds by the two NF membranes (transmembrane pressure $500 \mathrm{kPa}$, pH 7.5; initial concentration of compounds $0.5-0.8 \mathrm{mg} \mathrm{L}^{-1}$ ).

\begin{tabular}{lccccc}
\hline Membrane/ionic strength & Flux $\left(\mathrm{L} \mathrm{m}^{-2} \mathrm{~h}^{-1}\right)$ & Dimethyl phthalate (\%) & Diethyl phthalate (\%) & Acenaphthylene (\%) & Phenanthrene (\%) \\
\hline NF90 & & & & & \\
$10 \mathrm{mM}$ & 34.6 & 95.0 & 96.0 & 91.2 & 96.0 \\
$20 \mathrm{mM}$ & 37.1 & 93.0 & 95.0 & 91.2 & 93.1 \\
NF270 & & & & & \\
$10 \mathrm{mM}$ & 72.3 & 65.8 & 75.6 & 87.3 & 92.5 \\
$20 \mathrm{mM}$ & 87.3 & 25.0 & 33.3 & 82.4 & 88.6 \\
\hline
\end{tabular}

NF membranes were fouled by humic acid. Table 4 shows the rejection of dimethyl phthalate, diethyl phthalate, acenaphthylene, and phenanthrene by the two membranes. For NF90, an increase in the ionic strength of the feed solution slightly decreased the rejection of the compounds. In contrast, the rejection of pollutions by NF270 decreased significantly as the ionic strength increased, especially for dimethyl phthalate and diethyl phthalate. The observed decrease in rejection was attributed to the swelling of membrane pores, a reduction in the compound's hydrodynamic radius, or a combination of these two phenomena $[1,30,31]$. The charge density of NF membranes depends on the presence of salts at a constant $\mathrm{pH}$ (which was maintained in the present study). Adding salt to the solution resulted in a greater concentration of counterions in the electrical double layer at the surface of the membrane pores, which induced pore swelling and electrical doublelayer compaction. As a result, the apparent pore radius increased. Alternatively, in a mixed solution of chemicals and salt, a lower apparent volume of hydrated compounds may be observed compared to in the absence of salt, and hydrated compounds can permeate more freely through the membrane. This effect becomes stronger when the salt concentration increases, which explains the observed decrease in the rejection rate with an increase in the ionic strength. This phenomenon was also confirmed by the observed increase in flux due to higher salt concentrations in the feed solution.

\subsubsection{Effects of the Transmembrane Pressure on Rejection} and Permeate Flux. To investigate the influence of transmembrane pressure on the performance of the membranes, experiments were performed at 500,600 , and $700 \mathrm{kPa}$. In the present study, dimethyl phthalate, the most hydrophilic compound among the six tested chemicals, was used. Regardless of the mechanism of adsorption, the effect of pressure should be evident. Table 5 shows the rejection of dimethyl phthalate and the permeate flux at different transmembrane pressures for the two membranes. The rejection of dimethyl phthalate decreased with an increase in the transmembrane pressure for both NF90 and NF270 nanofiltration membranes, and the permeate flux increased with an increase in the transmembrane pressure for both membranes. These results are in accordance with those of previous studies [32], which showed that the (initial) fluxes of membranes varied almost linearly with the applied pressure. Nevertheless, different trends were observed during long-term filtration. Overall, the influence of pressure on the performance of NF270 membranes was more pronounced than for NF90.
TABLE 5: Influence of transmembrane pressure on dimethyl phthalate rejection and permeate flux (the feed solution contained $800 \mathrm{mg} \mathrm{L}^{-1}$ dimethyl phthalate; $\mathrm{pH} 7.5,10 \mathrm{mM} \mathrm{NaCl}$ ).

\begin{tabular}{lcccc}
\hline $\begin{array}{l}\text { Transmembrane } \\
\text { pressure }(\mathrm{kPa})\end{array}$ & $\begin{array}{c}\text { Flux } \\
\left(\mathrm{L} \mathrm{m}^{-2} \mathrm{~h}^{-1}\right)\end{array}$ & $\begin{array}{c}\text { Rejection } \\
(\%)\end{array}$ & $\begin{array}{c}\text { Flux } \\
\left(\mathrm{L} \mathrm{m}^{-2} \mathrm{~h}^{-1}\right)\end{array}$ & $\begin{array}{c}\text { Rejection } \\
(\%)\end{array}$ \\
\hline 500 & 43.4 & 95.8 & 65.2 & 65.8 \\
600 & 57.2 & 95.0 & 88.5 & 17.9 \\
700 & 66.5 & 92.5 & 108 & 14.0 \\
\hline
\end{tabular}

\section{Conclusion}

Rejection of PAHs and PAEs by NF was governed by steric hindrance (or size exclusion) and adsorption to the membrane surface and pore structure. Under both fouled and clean membrane conditions, higher rejection rates of all six selected micropollutants were achieved with the tight nanofiltration NF90 membrane compared to with the loose nanofiltration NF270 membrane. Although fouling had a negligible effect on the rejection of micropollutants by the NF90 membrane, considerable effects were observed with the NF270 membrane, which possessed a larger pore size. The observed enhancement in the rejection of micropollutants by fouled NF270 membranes was attributed to pore blocking and hydrophobic interactions between the membrane and organic micropollutants. The rejection of PAHs and PAEs was influenced by the ionic strength and transmembrane pressure, which were affected by the structure and properties of the micropollutants and membrane.

\section{Conflict of Interests}

The author has no relevant affiliations or financial involvement with any organization or entity with a financial interest in or financial conflict with the subject matter or materials discussed in the paper. This includes employment, consultancies, honoraria, stock ownership or options, expert testimony, grants or patents received or pending, or royalties.

\section{Acknowledgments}

This work was supported by the National Natural Science Foundation of China (no. 21137003) and Science Technology Department of Zhejiang Province (2014C33059). 


\section{References}

[1] Y. Zhang, C. Causserand, P. Aimar, and J. P. Cravedi, "Removal of bisphenol A by a nanofiltration membrane in view of drinking water production," Water Research, vol. 40, no. 20, pp. 3793-3799, 2006.

[2] J. Radjenović, M. Petrović, F. Ventura, and D. Barceló, "Rejection of pharmaceuticals in nanofiltration and reverse osmosis membrane drinking water treatment," Water Research, vol. 42, no. 14, pp. 3601-3610, 2008.

[3] Y. Shim, W. G. Rixey, and S. Chellam, "Influence of sorption on removal of tryptophan and phenylalanine during nanofiltration," Journal of Membrane Science, vol. 323, no. 1, pp. 99-104, 2008.

[4] L. Wang, C. Albasi, V. Faucet-Marquis et al., "Cyclophosphamide removal from water by nanofiltration and reverse osmosis membrane," Water Research, vol. 43, no. 17, pp. 41154122, 2009.

[5] C. Bellonaa, M. Martsa, and J. E. Drewesa, "The effect of organic membrane fouling on the properties and rejection characteristics of nanofiltration membranes," Separation and Purification Technology, vol. 74, no. 1, pp. 44-54, 2010.

[6] A. de Munari, A. J. C. Semiao, and B. Antizar-Ladislao, "Retention of pesticide Endosulfan by nanofiltration: influence of organic matter-pesticide complexation and solute-membrane interactions," Water Research, vol. 47, no. 10, pp. 3484-3496, 2013.

[7] V. Yangali-Quintanilla, A. Sadmani, M. McConville, M. Kennedy, and G. Amy, "Rejection of pharmaceutically active compounds and endocrine disrupting compounds by clean and fouled nanofiltration membranes," Water Research, vol. 43, no. 9, pp. 2349-2362, 2009.

[8] L. D. Nghiem and S. Hawkes, "Effects of membrane fouling on the nanofiltration of trace organic contaminants," Desalination, vol. 236, no. 1-3, pp. 273-281, 2009.

[9] A. M. Comerton, R. C. Andrews, D. M. Bagley, and P. Yang, "Membrane adsorption of endocrine disrupting compounds and pharmaceutically active compounds," Journal of Membrane Science, vol. 303, no. 1-2, pp. 267-277, 2007.

[10] A. J. C. Semião and A. I. Schäfer, "Removal of adsorbing estrogenic micropollutants by nanofiltration membranes. Part A-experimental evidence," Journal of Membrane Science, vol. 431, pp. 244-256, 2013.

[11] L. D. Nghiem, A. I. Schäfer, and M. Elimelech, "Removal of natural hormones by nanofiltration membranes: measurement, modeling, and mechanisms," Environmental Science and Technology, vol. 38, no. 6, pp. 1888-1896, 2004.

[12] C. Y. Tang, Y.-N. Kwon, and J. O. Leckie, "Characterization of humic acid fouled reverse osmosis and nanofiltration membranes by transmission electron microscopy and streaming potential measurements," Environmental Science \& Technology, vol. 41, no. 3, pp. 942-949, 2007.

[13] L. D. Nghiem, D. Vogel, and S. Khan, "Characterising humic acid fouling of nanofiltration membranes using bisphenol A as a molecular indicator," Water Research, vol. 42, no. 15, pp. 40494058, 2008.

[14] K. Listiarini, D. D. Sun, and J. O. Leckie, “Organic fouling of nanofiltration membranes: evaluating the effects of humic acid, calcium, alum coagulant and their combinations on the specific cake resistance," Journal of Membrane Science, vol. 332, no. 1-2, pp. 56-62, 2009.
[15] R. Lamsal, S. G. Harroun, C. L. Brosseau, and G. A. Gagnon, "Use of surface enhanced Raman spectroscopy for studying fouling on nanofiltration membrane," Separation and Purification Technology, vol. 96, pp. 7-11, 2012.

[16] A. R. D. Verliefde, E. R. Cornelissen, S. G. J. Heijman et al., "Influence of membrane fouling by (pretreated) surface water on rejection of pharmaceutically active compounds (PhACs) by nanofiltration membranes," Journal of Membrane Science, vol. 330, no. 1-2, pp. 90-103, 2009.

[17] M. A. Zazouli, H. Susanto, S. Nasseri, and M. Ulbricht, "Influences of solution chemistry and polymeric natural organic matter on the removal of aquatic pharmaceutical residuals by nanofiltration," Water Research, vol. 43, no. 13, pp. 3270-3280, 2009.

[18] J. Shen, X. Jin Yang, and A. I. Schäfer, "Quantification of hormone-humic acid interactions in nanofiltration," Environmental Science \& Technology, vol. 46, no. 19, pp. 10597-10604, 2012.

[19] F. Wang, X. Xia, and Y. Sha, "Distribution of phthalic acid esters in Wuhan section of the Yangtze River, China," Journal of Hazardous Materials, vol. 154, no. 1-3, pp. 317-324, 2008.

[20] L. Z. Zhu, Y. Y. Chen, and R. B. Zhou, "Distribution of polycyclic aromatic hydrocarbons in water, sediment and soil in drinking water resource of Zhejiang Province, China," Journal of Hazardous Materials, vol. 150, no. 2, pp. 308-316, 2008.

[21] F. Zeng, K. Y. Cui, Z. Y. Xie et al., "Occurrence of phthalate esters in water and sediment of urban lakes in a subtropical city, Guangzhou, South China," Environment International, vol. 34, no. 3, pp. 372-380, 2008.

[22] L. Patrolecco, N. Ademollo, S. Capri, R. Pagnotta, and S. Polesello, "Occurrence of priority hazardous PAHs in water, suspended particulate matter, sediment and common eels (Anguilla anguilla) in the urban stretch of the River Tiber (Italy)," Chemosphere, vol. 81, no. 11, pp. 1386-1392, 2010.

[23] IARC, IARC Monographs on the Evaluation of the Carcinogenic Risk of Chemicals to Humans, vol. 1-42 of Overall Evaluation of Carcinogenity: An Updating of IAPC Monographs, supplement 7, International Agency for Research on Cancer, Lyon, France, 1987.

[24] EURAR, European Union Risk Assessment Report on Dibutyl 8 Phthalate. 1st Priority List, vol. 29, Institute of Health and Consumer Protection (IHCP), European Chemicals Bureau, 2004.

[25] EU-RAR, European Union Risk Assessment Report on Benzyl Butyl Phthalate (BBP), vol. 76, 3rd Priority List, Institute of Health and Consumer Protection (IHCP), European Chemicals Bureau, 2007.

[26] J. Oehlmann, U. Schulte-Oehlmann, W. Kloas et al., "A critical analysis of the biological impacts of plasticizers on wildlife," Philosophical Transactions B, vol. 364, no. 1526, pp. 2047-2062, 2009.

[27] R. E. Ney, Where Did That Chemical Go: A Practical Guide to Chemical Fate and Transport in the Environment, vol. 192, Van Nostrand Reinhold, New York, NY, USA, 1990.

[28] S. Lee and M. Elimelech, "Relating organic fouling of reverse osmosis membranes to intermolecular adhesion forces," Environmental Science and Technology, vol. 40, no. 3, pp. 980-987, 2006.

[29] L. D. Nghiem, P. J. Coleman, and C. Espendiller, "Mechanisms underlying the effects of membrane fouling on the nanofiltration of trace organic contaminants," Desalination, vol. 250, no. 2, pp. 682-687, 2010. 
[30] G. Bargeman, J. M. Vollenbroek, J. Straatsma, C. G. P. H. Schroën, and R. M. Boom, "Nanofiltration of multi-component feeds. Interactions between neutral and charged components and their effect on retention," Journal of Membrane Science, vol. 247, no. 1-2, pp. 11-20, 2005.

[31] A. Bouchoux, H. R.-D. Balmann, and F. Lutin, "Nanofiltration of glucose and sodium lactate solutions: variations of retention between single- and mixed-solute solutions," Journal of Membrane Science, vol. 258, no. 1-2, pp. 123-132, 2005.

[32] C. Y. Tang, Y.-N. Kwon, and J. O. Leckie, "Fouling of reverse osmosis and nanofiltration membranes by humic acid-effects of solution composition and hydrodynamic conditions," Journal of Membrane Science, vol. 290, no. 1-2, pp. 86-94, 2007. 

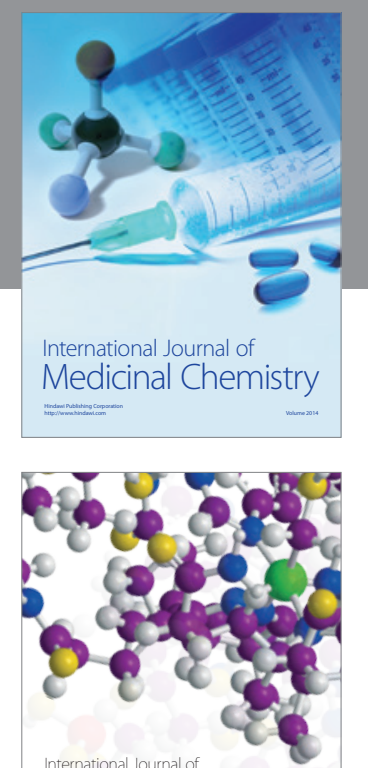

\section{Carbohydrate} Chemistry

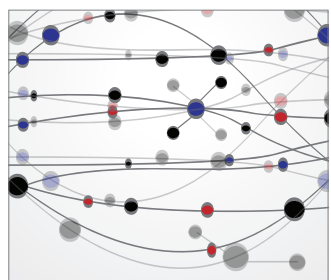

The Scientific World Journal
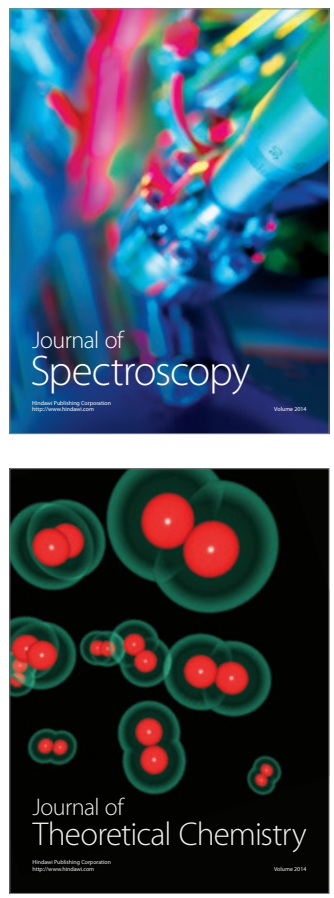
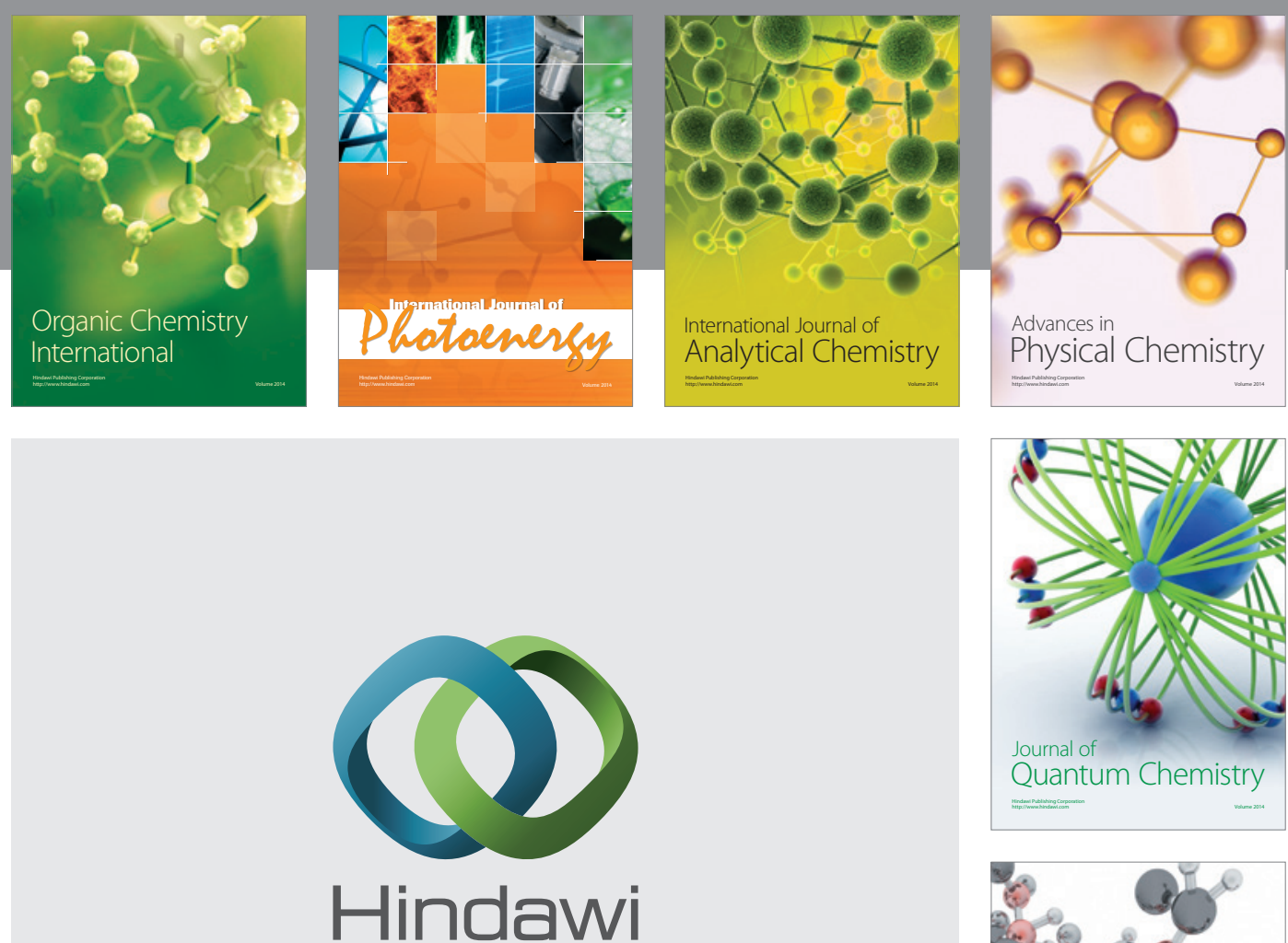

Submit your manuscripts at

http://www.hindawi.com

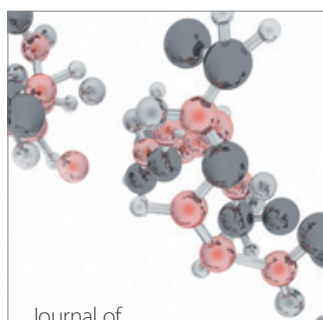

Analytical Methods

in Chemistry

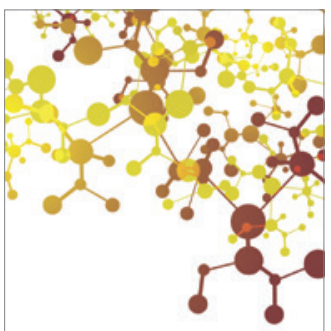

Journal of

Applied Chemistry

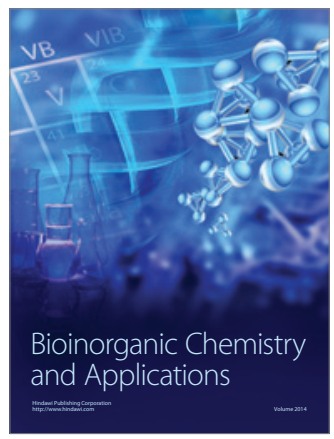

Inorganic Chemistry
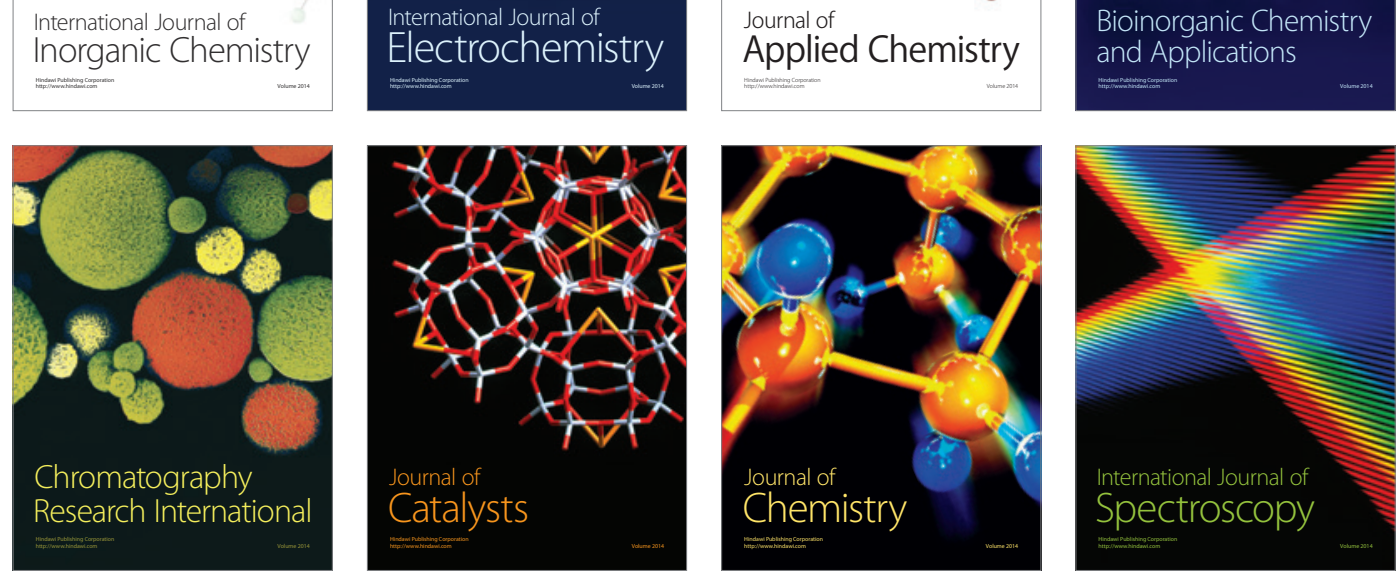